\title{
A SOCIEDADE EM REDE E AS DOENÇAS EMERGENTES: UMA PROPOSTA BASEADA NA UTILIZAÇÃO EXCESSIVA DAS TECNOLOGIAS DIGITAIS*
}

NETWORK SOCIETY AND EMERGING DISEASES: A PROPOSAL ON THE EXCESSIVE USE OF

DIGITAL TECHNOLOGIES

\section{Bruno Mello Correa de Barros ${ }^{1}$, Matheus Lima Roldão²}

RECEBIDO EM: 23/02/2017 / APROVADO EM: 20/03/2017

DOI: $10.5902 / 2317175825959$

\section{RESUMO}

Este artigo tem como objetivo debatera utilização excessiva das tecnologias digitaistípicas da sociedade em rede a partir da perspectiva da emergência de doenças relacionadasa essa utilização. Assim, pretende-se explorar se existe uma relação direta entre as novas tecnologias informacionais e as doenças emergentes da sociedade em rede.Nesse sentido, para a realização do presente trabalho, optou-se por empregar o método de abordagem indutivo, partindo de uma concepção mais restrita, baseada na perspectiva da morfologia da sociedadeem rede, alargando-se tal prerrogativa para a observância das novas doenças ocasionadas por esse uso constante de tecnologias no cotidiano dos indivíduos. Também foi utilizado o método de procedimento funcionalista, consubstanciado com a pesquisa documental e bibliográfica.Por fim, verificou-se a emergência de novas doenças em decorrência da utilização maciça e potencial das novas tecnologias digitais, como as Tecnologias da Informação e Comunicação (TIC), o que flagrantemente provoca e traz à tona um novo problema de saúde pública, evidenciando a imediata necessidade de uma estruturação moderna e eficaz dos mecanismos de saúde para tratar desse fenômeno, característica de uma sociedade em rede.

Palavras-chave: Doenças; Distúrbios; Saúde; Sociedade em rede; Tecnologias digitais.

\footnotetext{
* Pesquisa realizada com apoio da Coordenação de Aperfeiçoamento de Pessoal de Ensino Superior (CAPES). 1 Mestre em Direito pelo Programa de Pós-Graduação em Direito - PPGD da Universidade Federal de Santa Maria - UFSM. Área de Concentração: Direitos Emergentes na Sociedade Global. Linha de Pesquisa: Direitos na Sociedade em Rede. Professor do Curso de Direito da Faculdade Metodista de Santa Maria - FAMES Bolsista pela Coordenação de Aperfeiçoamento de Pessoal de Ensino Superior - CAPES de fevereiro de 2016 a março de 2017.

2 Acadêmico do Curso de Medicina da Universidade Federal de Santa Maria - UFSM.
} 
A SOCIEDADE EM REDE E AS DOENÇAS EMERGENTES:

UMA PROPOSTA BASEADA NA UTILIZAÇÃO EXCESSIVA DAS TECNOLOGIAS DIGITAIS

\begin{abstract}
This article aims to discuss the excessive use of digital technologies typical of the network society from the perspective of the emergence of diseases related to such use. Thus, it is intended to explore whether there is a direct relationship between the new information technologies and the emerging diseases of the network society. In this sense, for the accomplishment of the present work, it was chosen to use the method of inductive approach, starting from a more restricted conception, based on the perspective of the morphology of the network society, widening such prerogative for the observance of the new diseases caused by this constant use of technologies in the daily life of individuals. It was also used the method of functionalist procedure, consubstantiated with the documentary and bibliographic research. Finally, new diseases emerged as a result of the massive and potential use of new digital technologies, such as Information and Communication Technologies (ICT), which blatantly provoke and bring to the surface a new public health problem, evidencing the immediate need for a modern and effective structuring of the health mechanisms to deal with this phenomenon, characteristic of a networked society.
\end{abstract}

Keywords: Cheers;Diseases; Disturbances; Digital technologies; Network society.

\title{
1 Introdução
}

As tecnologias sempre ocuparam o papel de vetor das transformações das relações humanas. Durante o período da Revolução Industrial, as nuances de desenvolvimento puderam ser vistas com maior exponencialidade, devido às grandes e profundas transformações ocasionadas,em um primeiro momento, na produção de produtos e bens e, posteriormente, no setor de serviços. Após esse período da mecanização,surgiu o paradigma informacional, que passou a dominar a tônica das relações, uma vez que o conhecimento e a informação passaram a permear o progresso técnico-científico, permitindo o deslocamento da economia do material para o imaterial.

Dessa forma, tendo como cerne o conhecimento e a informação, a economia passou a ser remodelada, e tais estruturas passaram a se constituir em novos ativos econômicos, de grande importância para as relações comerciais, políticas e jurídicas entre nações, Estados, empresas e diversos outros setores de atividades. Logo, pode-senotarque a sociedade sempre foi alvo de transformação nos seus mais variados âmbitos, implicandomutações sociais, políticas, econômicas e culturais, e que geralmente esses movimentos de mudanças estiveram imbricados com o desenvolvimento e a especialização das tecnologias. Em decorrênciada Revolução Industrial do século XIX, observou-se a mudança da estratificação social com a ascensão da burguesia, a emergência da classe trabalhadora, a troca da produção manufaturada e artesanal pela utilização das máquinas, a produção em larga escala e o progresso técnico atrelado ao informacionalismo.

O século XXI é, assim, marcado pela ascensão das Tecnologias da 
Informação e Comunicação (TIC), incluindo toda a gama de ferramentas relacionadasà internet, tais como redes sociais, aplicativos e plataformas digitais. Nesse contexto, novos contornos puderam ser observados, como a grande utilização das redes digitais, a facilidade de comunicação por meio das conexões céleres e a modernização dos serviços da Administração Pública. Entretanto, àmedida que a sociedade e os seus atores sociais se expõem continuamente aos meios informacionais ligados à tecnologia, também se descortinam problemas e distúrbios causados pela conectividade.

Nesse sentido, o presente artigo visa discutir o relevo social da utilização das tecnologias informacionais e da globalização, sob o enfoque da saúde pública, especificamente da problemática envolvendo as doenças e os distúrbios provenientes do uso excessivo e da superexposição às TIC, que têm por base a internet e o computador. Pretende-se, dessa maneira, explorar a relação existente entre as novas tecnologias e os distúrbios de saúde observados hodiernamente.

Sendo assim, optou-se por dividir esteartigo em dois eixos principais. 0 primeiro destina-se a elencar as dinâmicas da sociedade em rede, deixando claras as nuances da informação no contexto contemporâneo e demarcando o peso circunstancial das novas tecnologias informacionais e do progresso técnico e científico para o contexto atual atrelado às dinâmicas da globalização. Como marco teórico referente à sociedade em rede,são utilizados os escritos do sociólogo espanhol Manuel Castells. O segundo eixo visa discutir os novos distúrbios e problemas de saúde relacionados à superexposição e utilização em demasia das tecnologias digitais, mostrando a necessidade de reestruturação dos serviços de saúde, a partir da emergência dessas novas doenças na sociedade em rede.

Logo, para a execução do presente trabalho, optou-se por utilizar o método de abordagem indutivo, partindo de uma concepção mais restrita, baseada na perspectiva da morfologia da sociedade em rede e alargando tal prerrogativa para a observância das novas doenças ocasionadas por esse uso constante de tecnologias no cotidiano dos indivíduos. Também se empregouo método de procedimento funcionalista, consubstanciado com a pesquisa documental e bibliográfica.

Cumpre ressaltar que este estudo pretende expor uma temática nova, emergente e em constante mutação, não objetivando, entretanto,exaurir o assunto, especialmente pela enormidade de questões essenciais e peculiares atreladas ao tema e por não ser possível desdobrar em um artigo científicotoda a gama concernente à temática ora explorada. Assim, apesar de ser uma questão interdisciplinar, a resposta para o problema proposto requer reflexões específicas sobre o tema. 


\title{
2 As Tecnologias da Informação e Comunicação (TIC) e a globalização na sociedade em rede
}

Nesta seção,o intento consiste em discorrer acerca das Tecnologias da Informação e Comunicação, de modo a configurar a sua relação com a globalização a partir da morfologia da sociedade em rede. Para isso, optouse por utilizar como marco teórico os estudos produzidos pelo sociólogo espanhol Manuel Castells, tendo em vista que suas proposições conseguem abarcar com maior fidelidade as dinâmicas de transformações observadas na contemporaneidade em virtude dos recursos tecnológicos. Já no que diz respeito aos riscos provenientes do uso desses recursos tecnológicos, utiliza-se como marco teórico basilar a produção de Anthony Giddens.

Dessa maneira, vislumbra-se que as tecnologias e seu uso propiciaram muitas modificações na estrutura social. Os séculos XVII e XIX deixarammarcas importantes para a humanidade, a exemplo da já mencionada Revolução Industrial,que combinada com outros ventos, transformou por meioda tecnologia a sociedadee a civilização do mundo inteiro (DRUCKER,1994). Dessa forma, o panorama da sociedade modificou-se com o passar do tempo, bem como o aperfeiçoamento das máquinas e dos demais equipamentos, o que gerou mais lucro, fortificando a economia e ampliando os espaços públicos e a oportunidade de trabalho (BARROS; RICHTER, 2013). Nesse sentido, diversos elementos constitutivos deram os contornos para todas as épocas e eras industriais vivenciadas ${ }^{3}$.

Sobre a transição da sociedade industrial para a pós-industrial, De Masi (2000, p. 328) afirma:

\begin{abstract}
A transição foi caracterizada pela passagem de uma sociedade na qual o setor econômico dominante era secundário (trabalho, indústria,agricultura), cujo modelo de vida era focado nas instalações industriais e fábricas, para a valorização de produtos e serviços do setor terciário (transporte, saúde, instituições de pesquisa, cultura e lazer). Nesse cenário, emergiram novas estruturas de classe e instituições básicas, como se observou com as grandes empresas e institutos de comunicação que outrora se valiam de meios de produção e matéria-prima; passou-se a valorizar os recursos da inteligência, informação e conhecimento. Estes sinais de mutação demarcaram o esgotamento da sociedade industrial e a emergência da sociedade pós-industrial.
\end{abstract}

Assim,o desenvolvimento dos meios tecnológicos ampliou tanto que novos recursos puderam emergir, como, por exemplo, a criação e o aperfeiçoamento das TIC, as quais, na visão de Sanches (2003), podem ser definidas como um conjunto de recursos tecnológicos usados para produzir

3 Segundo Rifkin (apud BELL, 1973), a Era Industrial foi marcada pelo uso da força bruta, do corpo e da energia física, em contrapartida à Era do Acesso, que é mais imaterial e cerebral, pois o conhecimento é meta sagrada. Em outras palavras, o valor-trabalho da sociedade industrial foi substituído pelo valor-saber da sociedade pós -industrial, tornando-se decisivas, nesse período de transformações, a centralidade do conhecimento teórico, a primazia da teoria sobre o empirismo e a codificação do conhecimento em sistemas abstratos de símbolos. 
e disseminar informações. Dentre tais recursos, salienta-se o telefone (fixo e celular), o fax, a televisão, as redes (de cabo ou fibra ótica) e o computador. No que concerne especificamente ao computador, quando ocorre a conexão entre dois ou mais computadores, cria-se uma rede, e a principal rede existente atualmente é a internet.

Por sua vez, Veloso (2011, p. 49) aponta as TIC como o "conjunto de dispositivos, serviços e conhecimentos relacionados a uma determinada infraestrutura, composta por computadores, softwares, sistemas de redes", os quais teriam a capacidade de produzir, processar, distribuir informações para organizações e sujeitos sociais. Uma característica fundamental que diferencia esse aporte tecnológico dos demais é o fato de as TIC serem fruto do imbricamento e da convergência das telecomunicações com a informática e a computação.

Nesse sentido, as TIC superam e transformam as formas de criação, transmissão, armazenamento e significação das informações próprias de sistemas anteriores, instaurando a possibilidade de novas lógicas e novas articulações de linguagens, com base em novos suportes e em novas máquinas dotadas de grande capacidade de armazenamento, processamento e troca de informações de alta velocidade (BONILLA, 2005). Logo, em todas essas áreas, a tecnologia tem trazido novas linguagens, possibilidades e formas de expressão, assim como novos conhecimentos, pensamentos, e, consequentemente, desafios, sejam eles sociais, culturais, políticos ou jurídicos. Outrossim, "a tecnologia não é somente a ciência e as máquinas, é também tecnologia social e organizativa" (CASTELLS, 1999, p. 5).

É nessa perspectiva social e organizativa que Castells explora a nova morfologia da sociedade, a qual denominou informacional, global e em rede, para identificar suas características fundamentais. Nessa senda, Castells afirma:

É informacional porque a produtividade e a competitividade de unidades ou agentes nessa economia (sejam empresas, regiões ou nações) dependem basicamente de sua capacidade de gerar, processar e aplicar, de forma eficiente a informação baseada em conhecimentos. É global por que as principais atividades produtivas, o consumo e a circulação, assim como seus componentes (capital, trabalho, matéria-prima, administração, informação, tecnologia e mercados) estão organizados em escala global, diretamente ou mediante uma rede de conexões entre agentes econômicos. É rede porque, nas novas condições históricas, a produtividade é gerada, e a concorrência é feita em uma rede global de interação entre redes empresariais (2003, p. 119).

Na proposta fomentada por Castells e outros teóricos, a informação torna-se um ativo econômico de suma importância para o desenvolvimento social, cultural e político das nações globalizadas, de modo a compor a estrutura de grandes empresas e corporações, que passaram a investir em tecnologias informacionais, dando suporte a uma nova contextualização 
A SOCIEDADE EM REDE E AS DOENÇAS EMERGENTES:

UMA PROPOSTA BASEADA NA UTILIZAÇÃO EXCESSIVA DAS TECNOLOGIAS DIGITAIS

social. O desenvolvimento das TIC, em especial da rede mundial de computadores (internet) e de seu ambiente informacional (Web 2.0), tem provocado mudanças significativas quanto às formas de produção de conteúdo informacional (ARAYA; VIDOTTI, 2009) e tem trazido à tona novos desafios e enfrentamentos, como distúrbios e problemas de saúde.

Cabe ressaltar que a ideia de sociedade em rede carrega implícita uma lógica de coexistência e de nãosubstituição imediata. Ou seja, as sociedades em rede coexistem com as sociedades industriais, como estas coexistiram (e por vezes ainda coexistem) com elementos das sociedades de características majoritariamente agrárias (CARDOSO, 2007). Outro fenômeno que tem grande influência na constituição de uma nova estratificação social baseada na tecnologia e nas redes de conexão é a globalização, que, na visão de André-Jean Arnaoud (1999), pode ser entendida como um paradigma ou como um valor paradigmático para justificar o interesse dos mercados de capitais. No entanto, a globalização econômica seguida como paradigma torna-se uma ameaça se ostentar ideais puramente neoliberais na defesa dos interesses econômicos.

A globalização pode fortalecer o fenômeno da universalização, que abre caminho para o aparecimento de outros atores de caráter transnacional que, para se desenvolverem livremente, mitigam, com o intuito de desvalorização, a identidade local, a soberania nacional, a cultura plural, a política, enfim, a existência da diversidade e do pluralismo dos Estados (ANDREUCCl; SANTOS, 2003). Nesse sentido, pode-se compreender que, apesar de o grande desenvolvimento tecnológico ter proporcionado a redução da percepção do espaço e do tempo, por outro lado esse desenvolvimento também obscurece a percepção dos processos de dominação e dependência entre as diversas escalas de relações humanas. Nesse sentido,conforme Ulrich Beck (1999, p. 157),“a globalização acentua o caráter processual da transnacionalidade", de modo que o caráter transnacional, que não reconhece fronteiras nem territórios, é favorecido pelo global, instaurando um momento histórico em que os limites espaciais já não são relevantes como marcos fronteiriços de soberania ante o capital.

Assim sendo, sob essa perspectiva, a sociedade em rede é potencialmente afetada pelas dinâmicas da globalização, as quais atuam como um processo controlado, de larga escala, que se desenvolve pelos Estados Nacionais, a partir da força econômica das grandes empresas, que passam a dominar setores e gerir determinadas fontes de riquezas e poder. Nessa configuração, ingressam de maneira substancial os recursos tecnológicos, uma vez que a informação e o conhecimento pautam esses instrumentos, que se alastram como poderosos vetores de dominação e ingerência. Dessa maneira, ao mesmo tempo que possibilitam o crescimento pessoal, científico, cultural, econômico, jurídico e político, escravizam a partir do seu utilitarismo cotidiano.

Nesse contexto, algumas mudanças vêm à tona, pois assuntos tratados no âmbito dos Estados ou das sociedades estatais passam a ser de interesse comum da humanidade, como, por exemplo, a prevenção contra os riscos 
do desenvolvimento ligados ao progresso tecnológico, o qual transforma a sociedade pós-moderna em uma sociedade mundial do risco. A esse respeito, Anthony Giddens (2000)menciona que o risco se refere a infortúnios ativamente avaliados para o futuro e propõe uma distinção entre dois tipos de risco - o risco externo e o risco interno ou fabricado. O risco externo consiste no risco experimentado, vindo, por exemplo, da natureza; enquanto que o risco fabricado ou criado decorre do impacto do crescente conhecimento e desenvolvimento, especialmente em razão de situações relativamente novasem termos históricos.

Nesse sentido, pode-se entender que a globalização aproxima parte das diferentes sociedades estatais, de modo que distâncias geográficas ou fronteiras não são obstáculos para uma integração dos povos, dando origem a identidades que significam como sendo uma sociedade mundial ou global. Nessa extensão da sociedade global, da globalização e do universalismo, estão os riscos da pós-modernidade, que acompanham o acelerado desenvolvimento dos mercados, da ciência e da tecnologia. Tais riscos, em geral, são de nocividade e alcance desconhecidos, não podendo, portanto, ser limitados a um espaço territorial (ANDREUCCI; SANTOS, 2003).

Bauman (2001, p. 43), ao refletir sobre a pós-modernidade, admite que "riscos e contradições continuam a ser socialmente produzidos; são apenas o dever e a necessidade de enfrentá-los que estão sendo individualizadas". Portanto, com base em tais reflexões acerca dos desafios globais deste século, da gama de potencialidades das TIC eda força da globalização na contemporaneidade, pode-se considerar que a garantia e a prevalência dos direitos humanos fundamentais, estabelecidos a partir do reconhecimento da pluralidade de identidades diante dos riscos da pós-modernidade, é uma necessidade que se impõe, sendo forçoso buscar soluções jurídicas, sociais e atreladas à saúde para atender os novos reclamos da sociedade em rede.

Logo, o crescente desenvolvimento das tecnologias constrói e aperfeiçoa os instrumentos para as aplicações diversas de que o ser humano necessita. Entretanto, o caminho aberto pela internet perpassa qualquer outro meio já criado, uma vez que os usuários internautas se tornam reféns dessa gama de atribuições ofertadas pelos computadores e pela rede conectada (BARROS; RICHTER, 2013), o que proporciona, de igual maneira, que sejam descortinados muitos problemas, distúrbios de saúde e doenças relacionadas ao progresso técnico possibilitado pelas tecnologias informacionais.

Em escala planetária, observa-se uma profunda transformação econômica, social, cultural, política e jurídica, com migração e fluxo de capital e tecnologia, desrespeitando a antiga lógica dos Estados Nacionais rigidamente estabelecidos e hermeticamente fechados. Vivencia-se, desse modo, a implantação da sociedade em rede, com fulcro na informação e nas conexões instantâneas, as quais são consideradas pilares da nova economia. 
Sendo assim, feitas as considerações acerca das TIC, da globalização e da consolidação da sociedade em rede, cumpre atentar aos problemas oriundos da utilização (em demasia, muitas vezes) dos recursos tecnológicos pelas pessoas, tais como novas doenças. Ou seja, problemas graves de saúde e distúrbios atrelados à constância do uso de computador, internet, aplicativos digitais e toda a monta de programas e ferramentas tecnológicas que estão hodiernamente ao dispor dos indivíduos.

\section{As novas tecnologias sob a perspectiva dos distúrbios, das doenças emergentes e dos problemas de saúde na contemporaneidade}

Conforme exposto na seção anterior, as tecnologias foram os vetores de profundas transformações da humanidade, uma vez que por seu intermédio foi possível alcançar o pleno desenvolvimento da indústria, das empresas ligadas à mecanização do homem e das atividades de trabalho, assim comoo crescimento da intelectualidade e o aperfeiçoamento de variadas habilidades técnicas e atividades.Nesse sentido, Canclini (2008, p. 54) expõe que "[...] as redes virtuais alteram os modos de ver e ler, as formas de reunir-se, falar e escrever".

Todo esse crescimento e aperfeiçoamento ligados à tecnologia podem desencadear muitos problemas, especialmente quanto a doenças e distúrbios, os quais podem se apresentar como desafios à saúde pública. A noção atual de saúde pública ganha nitidez no Estado liberal burguês do final do século XVIII(CARVALHEIRO; MARQUES; MOTA, 2008). Já no início do século XXI, a constatação de que a ciência - que tem permitido o progresso da humanidade - é potencialmente geradora de riscos importantes implica novas mudanças ao conceito de saúde pública. Verifica-se, com efeito, que o controle desses riscos termina por escapar das mãos dos homens, especialmente porque o custo de mais algumas medidas de proteção se torna socialmente proibitivo (CARVALHEIRO; MARQUES; MOTA, 2008).

Por outro lado, a complexidade da vida atual faz com que não se considere absurda a hipótese de haver um limite técnico que impeça a maximização da proteção contra um perigo pouco provável, sob pena de aumentar outro. Observa-se, então, que o crescimento zero, o imperativo ecológico e a prevenção calculada dos riscos cada vez mais diversos passam a ter praticamente o mesmo significado, todos limitados pela impossibilidade de controle dos efeitos da atividade socialmente organizada (DALLARI, 2007). Por essa interpretação, o sentido da saúde torna-se um mandamento com efeitos normatizadores e, ao mesmo tempo, com uma marcada dimensão utópica, ou seja, um projeto que supera a ideologia e que, embora pretenda a universalidade, é socialmente reconhecida como um discurso particular, originário de uma parcela da sociedade (LUZ, 2003). 
Dentro desse contexto, ao longo dos anos muitas modificações foram sendo desenvolvidas e realizadas na área da saúde. Nos anos de 1970, por exemplo, ocorreu a criação do Ministério da Previdência, que passa a assistência médica do trabalhador para o Instituto Nacional do Seguro Social (INSS). Nessa nova configuração, acentua-se a divisão entre as ações de saúde pública como competência do estado e a assistência médica como responsabilidade do setor privado financiado por recursos públicos, particularmente os da Previdência Social (ZIONI; ALMEIDA, 2008).

Todavia, a medida mais expressiva de mudança nesse âmbito relacionado à saúde pública no Brasil foi a criação do Sistema Único de Saúde (SUS), o qual diz respeito ao "conjunto de ações e serviços de saúde prestados por órgãos e instituições Públicas Federais, Estaduais e Municipais, da Administração Direta e Indireta e das Fundações mantidas pelo Poder Público" e complementarmente "[...] pela iniciativa privada" (BRASIL, 1990). O SUS visa dar assistência à população baseando-se no modelo da promoção, proteção e recuperação da saúde, para que assim sejam procurados os meios - processos, estruturas e métodos - capazes de alcançar tais objetivos com eficiência e eficácia. Esses meios, orientados pelos princípios organizativos da descentralização, regionalização, hierarquização, resolutividade, participação social e complementaridade do setor privado, devem constituir-se em objetivos estratégicos que deem concretude ao modelo de atenção à saúde desejada para o SUS (ALMEIDA; CHIORO, 2002).

Assim, em tese o SUS deveria estar totalmente capacitado para a resolutividade dos problemas de saúde e das enfermidades da população; contudo, não é o que acontece. Nesse sentido,questionam-se as dimensões da imbricação das novas tecnologias com o ser humano, que acabam por desencadear novas modalidades de doenças, distúrbios e problemas relacionados, apontando, necessariamente, para um desafio a ser enfrentado pela saúde pública, na tentativa de sanar ou solucionar esses problemas.

A esse respeito, Postman (1994, p. 27) relata que "uma tecnologia nova não acrescenta nem subtrai coisa alguma, ela muda tudo". Sendo assim, muitas expressões da vida em sociedade foram remodeladas à luz das tecnologias e da informação dispersada na contemporaneidade, a tal ponto que novos hábitos foram sendo introduzidos, especialmente nas crianças e nos adolescentes que nascem em meios a essas tecnologias, configurando-se verdadeiros nativos digitais ${ }^{4}$, enquanto que os adultos experimentam e acabam por render-se a aprender a utilizar os novos instrumentos. Esse quadro indica que, no momento da introdução de novos mecanismos tecnológicos, novas relações e reações perpetradas por tais meios vão desenhando-se.

4 De acordo com Vosgerau e Bertoncello (2010), a expressão nativos digitais, criada por Marc Prensky, é aplicável a todos os nascidos após 1982, que cresceram em meio às tecnologias informacionais, em especial à internet, o que os torna familiarizados de tal maneira com tais tecnologias que dispensam escolas ou professores para as utilizarem. Os imigrantes digitais, por sua vez, isto é, aqueles que nasceram antes de 1982. demonstram menos familiaridade e necessitam de maior esforço para fazer uso das tecnologias. 
A SOCIEDADE EM REDE E AS DOENÇAS EMERGENTES:

UMA PROPOSTA BASEADA NA UTILIZAÇÃO EXCESSIVA DAS TECNOLOGIAS DIGITAIS

Cabe salientar que, com o acelerado processo de desenvolvimento das tecnologias como a internet, acentuou-se também a participação dessas tecnologias no diaadia das pessoas, fazendo com que sua assimilação e não ocorresse da mesma forma para todos. Assim, vislumbra-se um verdadeiro descompasso entre a introdução dessas tecnologias e a sua compreensão por parte daqueles que a utilizam (BARROS; RICHTER, 2013). Nesse sentido, é possível afirmar, levando-se em consideração a rapidez das relações, da competitividade, do trabalho e da necessidade de crescimento pessoal e profissional, que as TIC foram apropriadas pelos indivíduos como ferramentas potenciais para que tal quadro pudesse se perfectibilizar, o que levou à constância no seu uso, deixando de lado as consequências e a nocividade atreladas a esse uso.

De acordo com dados disponibilizados pelo Comitê Gestor da Internet no Brasil (CGI.Br), foi possível mapear alguns aspectos inerentes à utilização desses recursos de expertise tecnológica pela população. Verificou-se, assim, que a proporção de domicílios com acesso ao computador é de aproximadamente $50 \%$, enquanto que a proporção de domicílios com acesso à internet é de aproximadamente $51 \%$. Dentre os usuários da rede, $89 \%$ acessam a internet pelo telefone celular, e $65 \%$ o fazem por meio de um computador (de mesa, portátil ou tablet). Também se verificou que as conexões Wi-Fi estão presentes em $79 \%$ dos domicílios com acesso à internet. Logo, com base nos dados de 2015, a estimativa é de que 33,2 milhões de domicílios tenham acesso ao computador (CGI, 2016).

Tal pesquisa apontou, ainda,que a frequência do uso da internet pela população com acesso a esse meio passou de 53\%, em 2008, para 82\%, em 2015, o que demonstra uma real efervescência de indução e utilização das tecnologias informacionais e digitais por parte das pessoas (CGI, 2016).Nessa perspectiva, médicos, cientistas, pesquisadores e estudiosos detectaram e nominaram diversas doenças e distúrbios ocasionados pelo uso contínuo das TIC. Ingressam nessa configuração a chamada síndrome do toque fantasma, a nomophobia, a náusea digital ou cybersickness, a depressão de Facebook, a hipocondria digital, otranstorno de dependência de internet ${ }^{5}$, dentre outras doenças.

5 Síndrome do toque fantasma: ocorre quando o indivíduo acredita que determinado dispositivo móvel está vibrando, quando, na verdade, não está. Isso ocorre devido a mecanismos de respostas emitidos pelo cérebro levando o indivíduo a crer que, a todo instante, necessita consultar o dispositivo e verificar se existe algo que requer sua atenção; nomophobia: está relacionada diretamente à sensação de não poder se conectar prontamente, ou seja, uma sensação de privação tecnológica, ocasionada porque o indivíduo esqueceu o telefone ou porque a bateria acabou, o que o impede de receber as últimas informacões da timeline de uma rede social, por exemplo, gerando forte ansiedade; náusea digital ou cybersickness: corresponde a uma sensação de enjoo vivenciada quando se usam telas virtuais. Essa sensação se deve em grande parte ao efeito que faz com que os ícones e a tela de abertura pareçam estar se movendo dentro de um mundo tridimensional, abaixo do visor de vidro. Tais tonturas e náuseas resultantes de um ambiente virtual são explicadas por conta da sensação de movimento, mesmo quando não se está realmente se movimentando. É como se o cérebro estivesse sendo enganado; depressão de Facebook: diz respeito ao tempo dedicado a essa rede social e às postagens realizadas pelos usuários, que muitas vezes dizem respeito a festas, viagens e momentos de alegria, sucesso e entusiasmo. Aqueles que não se identificam com tal rotina acabam por desenvolver tal distúrbio, gerando melancolia, tristeza e depressão; hipocondria digital: corresponde à enxurrada de informações ofertadas pela internet. Os usuários que já possuem tendência à hipocondria, ou seja, à automedicação, procuram informações na internet sobre determinada doença, recebem diagnóstico e, a partir de então, por conta própria passam a executar procedimentos que visam trazer a cura à sua enfermidade. O perigo disso, segundo um estudo realizado pela Microsoft em 2008, é que autodiagnósticos feitos a partir de ferramentas de busca on-line geralmente levam buscadores aflitos a concluir o pior, o que pode causar novas ansiedades e a automedicação; transtorno de dependência da internet: diz respeito exatamente ao uso desmedido da tecnologia, ainda que os termos "dependência" e "transtorno" sejam um tanto controversos dentro da comunidade médica, que acredita que a compulsão da internet está relacionada a outras doenças (REVISTA BRASILEIROS, 2013). 
Todas essas enfermidades emergentes têm uma característica comum: a tecnologia. Nesse sentido, o dispositivo ou recurso tecnológico utilizado pelos indivíduos cotidianamente pode se tornar um vício ou uma doença, gerando, consequentemente, em longo prazo um problema de saúde pública, a ser enfrentado pelo Estado e pelos governos. Dessa forma, impende referir que a era informacional transformou o modo como o indivíduo se relaciona com os demais, que passou a apresentar comportamentos característicos e, por vezes, desconexos. O uso compulsivo da internet (Pathological Internet Use) transpõe o indivíduo ao espaço virtual, fazendo com que diminua suas atividades sociais e familiares, gerando, consequentemente, certo isolamento, além de distúrbios que passam pela dificuldade de controlar o tempo de uso do equipamento, problemas ocupacionais, alteração substancial do relógio biológico humano e problemas relacionados à ansiedade, à irritação, à agitação, à tensão e à depressão (BARROS; RICHTER, 2013).

Além das já mencionadas adversidades psíquicas provocadas pelo uso exacerbado da internet, do computador e dos demais meios tecnológicos, cumpre citar doenças físicas propiciadas por tal uso. Nesse rol, ingressa a Lesão por Esforço Repetitivo (LER), que consiste em uma doença provocada pelaexecução inadequada e excessiva de determinada atividade, que representa cerca de $70 \%$ das enfermidades que acometem o mercado de profissionais no Brasil (ERGONOMIA, DORT OU LER, 2017). É possível, igualmente, haver problemas na coluna vertebral, em decorrência da má postura e do tempo excessivo em que se permanece em uma mesma posição, levando, por exemplo, ao aparecimento de distúrbios comoartrose, lordose, cifose e, escoliose.

Outra possibilidade é o surgimento de problemas oculares em função da exposição em larga escala ao computador, que emite uma grande luminosidade. $O$ estresse aos músculos oculares ocorre por conta do contato com os pixels emitidos pelo eletrônico, ocasionando problemas como a síndrome do olho seco, por exemplo (FONSECA; ARRUDA; ROCHA, 2010, p. 200). Essa enfermidade é caudada pela ausênciado ato de piscar, o que resulta na evaporação das lágrimas, deixando os olhos sem lubrificação e nutrição córnea e gerando sintomas característicos, tais como irritação nos olhos e fortes dores de cabeça. Segundo estudos, pessoas saudáveis com o uso regular do computador, tendem a piscar entre 32 e $42 \%$ menos que o normal. Tal redução é uma reação do sistema nervoso que necessita de maiores informações e atenções visuais (FONSECA; ARRUDA; ROCHA, 2010, p. 200).

Sendo assim, a partir da interação propiciada pelos dispositivos móveis, pelo computador e por outras plataformas digitais, observa-se uma dependência cada vez maior desses recursos, uma vez que os indivíduos passaram a utilizar em tempo contínuo esses meios, dedicando boa parcela do seu dia a manter contato por meio de redes sociais e a executar atividades relacionadas ao trabalho, estudo e lazer. Nesse sentido, Canclini afirma que "a comunicação digital, especialmente a de caráter móvel por meio de 
A SOCIEDADE EM REDE E AS DOENÇAS EMERGENTES:

UMA PROPOSTA BASEADA NA UTILIZAÇÃO EXCESSIVA DAS TECNOLOGIAS DIGITAIS

celulares, proporciona ao mesmo tempo, interação interna e deslocalização, conhecimento e novas dúvidas" (2008, p. 52).

Dessa forma, além das enfermidades emergentes surgidas nesse período histórico por conta da forte indução tecnológica, tais hábitos podem gerar impacto na construção da identidade dos indivíduos e interferir em suas relações sociais. A esse respeito, Contrera esclarece:

\footnotetext{
O uso excessivo das tecnologias informacionais, sem finalidade específica, faz com que a pessoa se torne a própria mensagem, pois na falta do que comunicar ela se coloca no centro da mensagem. [...] Os contatos no ciberespaço não permitem que se desenvolva a verdadeira comunicação, que exige a mobilização dos sentidos como visão, audição, tato, olfato, paladar, tradicionais elementos da comunicação primária, muitos deles desconsiderados nesse novo processo comunicacional $(2002$, p. 68$)$.
}

Assim, muitas são as implicações decorrentes desse uso excessivo, bem como da amplitude informacional, que leva o indivíduo a dispersarse, carecendo de autodeterminação informativa, tendo emvista que recebe uma enorme carga de informação por tais meios e não sabe o que fazer efetivamente com esses recursos, de modo que não direciona essa informação para obter alguma vantagem. Nesse contexto, cabe citar os dados coletados pela Pesquisa Brasileira de Mídia 2015, que realiza um mapeamento dos hábitos de consumo de mídia pela população brasileira e que é desenvolvida pela Secretaria de Comunicação Social da Presidência da República.

Esses dados demonstram que o hábito de uso da internet é mais intenso hodiernamente, uma vez que os usuários das novas mídias ficam mais conectados. O tempo de exposição a esse meio ocorre é, em média, de $4 \mathrm{~h} 59 \mathrm{~min}$ por dia durante a semana e $4 \mathrm{~h} 24 \mathrm{~min}$ nos finais de semana, dados que, na Pesquisa Brasileira de Mídia 2014, eram em torno de 3h39min e 3h43min, respectivamente (BRASIL, 2014). Atualmente, muito desse tempo utilizado pelos indivíduos em frente às máquinas computadorizadas convergem para o acesso a redes sociais ${ }^{6}$, tais como Facebook, Twitter e outras redes que potencializam a comunicação humana em larga escala por meio eletrônico. A utilização das novas mídias ${ }^{7}$ na sociedade em rede é de toda a ordem, abrangendo aspectos como realização de negócios, estudo, lazer, comunicação, exercício de direitos e comércio eletrônico, o que marca o poderio da virtualidade e evidencia as nuances dos problemas daí oriundos, a exemplodas doenças emergentes.

A esse respeito, Ascensão (2002, p. 69) relata:

\footnotetext{
6 Redes sociais podem ser definidas como redes de comunicação marcadas por dois elementos centrais, os atores sociais (pessoas, instituições e grupos) e as conexões, que são as interações sociais desenvolvidas nesse meio. Rede é uma metáfora para observar os padrões de conexão de um grupo social, a partir de conexões estabelecidas entre os diversos atores (RECUERO, 2009).

7 As novas mídias podem ser assim apelidadas por consistirem em mediadores de comunicação interpessoal e meios de comunicação de massa, por atuarem como indutores da mudança organizacional e de novas formas de gestão do tempo e por procurarem a síntese da retórica textual e visual, promovendo novas audiências e ferramentas de reconstrução social (CARDOSO, 2007).
} 
A Internet permitiu a experimentação de um tipo de comunicação de âmbito mundial. Apresentou-se com um caráter atrativo, que levou a que os destinatários nela se empenhassem e adestrassem, e por outro lado ficassem dependentes deste modo de comunicação.

Assim, o que se pode verificar acerca de todo esse contexto é que as TIC, especialmente computador e internet, estão realizando profundas transformações na sociedade e nas relações humanas. Conforme Mattelart (1998, p. 7), "as redes de comunicação em tempo real estão configurando o modo de organização do planeta", abarcando a economia, a política, as implicações jurídicas e também as aspectos relacionados à saúde dos indivíduos, a qual se vê desafiada pelas novas doenças emergentes e pelos problemas surgidos nesse período. Cabe reforçar, ainda, que, a partir da constância desse uso, os problemas de saúde e a emergência de doenças dessa natureza tendem a aumentar, o que revela a necessidade de estruturação dos serviços de saúde pública para atender tais implicações.

No que concerne aos impactos trazidos pelas novas tecnologias, podese citar, ainda, a informatose, a normose informacional e a cibernose. A informatose consiste em um terno que designa "[...] distúrbios ou mesmo doenças causadas pelo excesso de fluxo de mensagens informacionais em relação a um só receptor, isto é, a uma só pessoa" (WEIL, 2000, p. 165). Dizem respeito especificamente às consequências patológicas do acúmulo de informações ou simplesmente do uso da informática em certas condições.

Já a normose ${ }^{8}$ informacional caracteriza os aspectos patogênicos da cultura informacional, podendo ser desencadeada pelas facilidades e pelos hábitos impostos pelas novas tecnologias de informação, apesar de tais facilidades trazerem benefícios (WEIL, 2000). Entretanto, Weil (2000) aponta que os trabalhos sobre a existência da informação como fenômeno cultural parecem configurar a existência de um consenso em torno da normalidade do uso da informática, em específico da internet, nesse processo de assimilação informacional.

A cibernose, por sua vez, termocriado pelo psicossociológo francês Van Bockstaelea partir de uma situação experimental, ou seja, uma socioanálise, segundo Weil (2000, p. 165) designa nós de estrangulamento nas comunicações. Weil retoma o termo para designar "[...] situações de perturbação de comunicações, com efeitos patogênicos sobre o sistema nervoso, ou funções mentais, causados na sua maioria pelo uso de aparelhos cibernéticos" (2000, p. 165).

Pode-se caracterizar a cibernose, portanto, pelos efeitos de atrofias de funções humanas devidas ao uso do computador, quadro que indica que, na

8 A normose é um sofrimento como a neurose e a psicose, e o consenso de conformidade que a rodeia impede os sujeitos de serem quem realmente são, pois precisam corresponder à imagem que os outros têm deles. Surge quando o sistema se encontra dominantemente equilibrado e mórbido, de modo que ser normal consiste em se ajustar à patologia reinante, mantendo, assim, o status quo (WEIL; LELOUP; CREMA, 2003). 
sociedade em rede, há uma completa dependência da máquina para realizar diversas atividades. Segundo exemplifica Weil (2000), o uso do telefone celular enquadra-se nessa situação, já que aqueles usuários que carregam o aparelho consigo permanentemente têmuma perda de liberdade, pois precisam atender às chamadas, sem saber se o assunto é urgente ou não. O autor ainda observa que, com essa utilização constante e dependência do celular, a comunicação é frequentemente interrompida, por diversos fatores, acarretando frustrações constantes entre os usuários.

Como consequências da cibernose, é possível identificar, segundo Weil (2000, p. 168), o desequilíbrio dos hemisférios cerebrais, tendo em vista quea capacidade de armazenar uma quantidade enorme de informação ou de treinar o raciocínio lógico, estimulada pela informática, é ligada ao hemisfério esquerdo do cérebro, enquanto que a criatividade, ligada ao hemisfério direito, seria pouco estimulada. No problema causado por essa atrofia da criatividade e da intuição, encontra-se a distorção de toda a cultura humana, dominada há milênios por uma normose machista, que reprimiu o lado direito do cérebro, isto é, as funções femininas de abertura, que são apenas uma expressão do confinamento da mulher no lar e da repressão do lado feminino na maioria dos homens.

Segundo Weil (2000), a atrofia da função numérica da mente humana consiste em mais uma consequência desse distúrbio. Nesse caso, o uso da máquina de calcular ou do computador para realizar operações aritméticas simples seria cada vez mais frequente entre os indivíduos. O uso dessa tecnologia diminui a habilidade da realização de um cálculo mental sem ajuda de uma máquina. $O$ autor questiona, com isso, se os indivíduos estariam caminhando para uma atrofia progressiva das funções de cálculo mental. Por fim, Weil (2000, p. 168) cita as frustrações nas comunicações e relações humanas, aspecto que concerne à perda de liberdade causada pelo uso das novas tecnologias digitais, já que seu uso poderia causar interrupções na comunicação intelectual e afetiva.

Esse quadro de novas doenças, que são emergentes da sociedade em rede, mostra-se preocupante, uma vez que, seos serviços públicos de saúde, sobretudo do SUS, já se revelam ineficazes em alguns aspectos e não conseguem atender na plenitude todos os chamados da população que carece de atendimento para as enfermidades típicas da sociedade, o que dizer então de novas demandas relacionadas ao uso da tecnologia. Portanto, uma atenção para tal tema deve ser dada com maior afinco, despertando um olhar atento dos gestores públicos e demais atores responsáveis, bem como também daqueles que têm o condão de direcionamento da educação de crianças e adolescentes, público esse que formará a força de trabalho da sociedade e que, desde o nascimento, já se utiliza das tecnologias informacionais.

Cabe ressaltar, assim, a potencial força das tecnologias na sociedade em rede e a iminência de problemas de saúde pública ocasionados pela constância 
do uso desses equipamentos, que levam à emergência de novas doenças e distúrbios, que provocam a erosão da saúde dos indivíduos, os quais se veem em situação de extrema vulnerabilidade, uma vez que a expertise tecnológica é uma realidade dura de combater, tendo como ponto de confluência a necessidade de tal recurso, muitas vezes, para o trabalho e, portanto, para a sobrevivência.

\section{Considerações finais}

Enquanto Henry Ford foi o símbolo de um modelo de capitalismo industrial - em que a produção e o consumo massivos foram regulados por meio do "Estado de Bem-Estar Social" -, Bill Gates é o símbolo de uma nova forma de capitalismo convergente caracterizado pela (re)regulamentação que vem ocorrendo nos últimos anos (CAPPARELLI; RAMOS; SANTOS, 1999). Esse cenário, típico do século XXI,evidencia as novas dinâmicas da sociedade, em que o capitalismo industrial se mostra acelerado e o progresso técnico-científico é uma realidade inafastável, que proporciona uma pluralidade de novaspossibilidades e também descortina novos desajustes nessa configuração social.

Nesse sentido, o cerne de desenvolvimento deste artigo consistiu em esclarecer as novas dinâmicas da sociedade em rede a partir de uma ótica que revela as doenças emergentes e os problemas e distúrbios de saúde causados pelo uso excessivo dos meios tecnológicos. Dessa forma, apresentouse,no primeiro eixo temático deste estudo, a sedimentação da sociedade em rede, a qual ocorreu, oportunamente, a partir da utilização das TIC, que são instrumentos de expertise tecnológica ligados ao conhecimento e à informação. Nesse espectro, vislumbrou-se também a Revolução Industrial e a mecanização desse período histórico, passando para a pós-modernidade e a economia do imaterial, baseada, sobretudo, nos ativos de poder da informação.

Em seguida, discutiu-se a ligação existente entre a edificação da sociedade em rede e a globalização e seus efeitos - esta é um fenômeno que tem por égide o estreitamento das relações estabelecidas entre Estados Nacionais, povos e nações, especialmente a partir do liame econômico, dando voracidade às dinâmicas que visam à consolidação do capital hegemônico de empresas, instituições e demais atores. Esse cenário prevê que todas as operações sejam realizadas por meio virtual, o que acrescenta novas forças à tecnologia e possibilita que os indivíduos se utilizem mais ainda de tais instrumentos em todos os campos de sua rotina.

Após a verificação da morfologia social em rede,iniciou-se um debate acercadas novas tecnologias sob a perspectiva das doenças emergentes, assim como dos distúrbios e dos problemas de saúde oriundos dessa configuração. Esse quadro de enfermidades foi revelado a partir de estudos ainda em construção, mas que já demonstram a tamanha gravidade dos distúrbios observados na contemporaneidade a partir do uso comprometedor das 
A SOCIEDADE EM REDE E AS DOENÇAS EMERGENTES:

UMA PROPOSTA BASEADA NA UTILIZAÇÃO EXCESSIVA DAS TECNOLOGIAS DIGITAIS

TIC. Dentro dessa perspectiva, incluem-se a síndrome do toque fantasma, a nomophobia, a náusea digital ou cybersickness, a depressão de Facebook, a hipocondria digital, o transtorno de dependência da internet, a normose informacional, a cibernose e a informatose.

Do mesmo modo, outras doenças foram diagnosticadas, tais como a Lesão por Esforço Repetitivo (LER), tendo em vista os movimentos repetidos realizados em frente ao equipamento tecnológico, bem como os problemas oculares, uma vez que a luminosidade apresentada pelos aparelhos eletrônicos pode auxiliar no desenvolvimento de problemas nos olhos e causar transtornos dessa natureza. Esse quadro emergente de doenças e problemas oriundos das tecnologias tem razão de ser levando-se em conta o uso excessivo de tais ferramentas e, preponderantemente, o tempo de exposição e manuseio de tais instrumentos, aspectos que podem ser verificados a partir dos dados aqui apresentados e extraídos da Pesquisa TIC Domicílios 2015, realizada pelo Comitê Gestor da Internet no Brasil, eda Pesquisa Brasileira de Mídia 2015, realizada pela Secretaria de Comunicação Social da Presidência da República, que mapeia os dados de consumo de mídia no país.

Portanto, a partir da literatura científica discutida, bem como dos dados científicos e das demais argumentações de autores e doutrinadores da temática ora explorada, verifica-se uma relação direta entre as novas tecnologias informacionais e os novos distúrbios de saúde. Essa configuração indicauma introdução cada vez maior das tecnologias digitais na contemporaneidade e no diaadia dos indivíduos, que delas se utilizam para atividades como trabalho, lazer, pesquisa, cultura e relações humanas. Nesse quadro, faz-se necessária uma postura ativa de gestores de saúde especialmente ligada à educação e ao conhecimento desses novos problemas de saúde, para que possam e saibam operacionalizar a cura de tais doenças e para que seja possível, assim,criar instrumentos determinantes na solução desses casos, como, por exemplo, a capacitação de médicos e demais profissionais de saúde.

Assim sendo, como as tecnologias são uma realidade inafastável, resta apenas um redirecionamento da sociedade: uma observância preliminar do conhecimento dessas doenças, da natureza dos casos e da iminência de um cuidado com os indivíduos. Caso contrário, os problemas relacionados a essas novas tecnologias digitais poderão se tornar um problema de saúde coletiva/ pública de extrema gravidade na sociedade em rede contemporânea. 


\section{Referências}

ALMEIDA, ES; CHIORO, A. Zioni F. Políticas Públicas e organização do sistema de saúde: antecedentes, reforma sanitária e o SUS. In: WSTPHAL MF; ALMEIDA, ES (Org.). Gestão de serviços de saúde: descentralização/ municipalização do SUS. São Paulo: Cortez, 2002.

ARAYA, Elizabeth Roxana Mass; VIDOTTI, Silvana Aparecida Borsetti Gregorio. Direito Autoral e Tecnologias de Informação e Comunicação no contexto da produção, uso e disseminação de informação: um olhar para as Licenças Creative Commons. In: Inf. \& Soc.: Est., João Pessoa, v.19, n.3, p. 39-51, set./dez.2009. Disponível em: <http://www.ies.ufpb.br/ojs/index.php/ies/article/view/3900>. Acesso em: 19 Fev. 2017.

ARNAOUD, André-Jean. O Direito entre Modernidade e Globalização: Lições de Filosofia do Direito e do Estado. Tradução de Patrice Charles Wuillaume. Rio de Janeiro: Renovar, 1999.

ASCENSÃO, José de Oliveira. Direito da Internet e da Sociedade da Informação. Rio de Janeiro: Forense, 2002.

ANDREUCCI, Álvaro Gonçalves Antunes; SANTOS, Queila Rocha Carmona dos. Globalização e Direito: Uma Convivência Responsável Diante dos Riscos Tecnológicos. In: Revista de Direito Brasileira, ano n 3, vol. 6, set. dez. 2003.

BARROS, Bruno Mello Correa de; RICHTER, Daniela. A Criança e o Adolescente Internauta - Doenças, Celeumas e Distúrbios: Uma análise Jurídica das Tecnologias da Informação e Comunicação sob a ótica do Princípio da Proteção Integral. In: XXIICongresso Nacional do Conpedi, São Paulo, de 13 a 16 de novembro de 2013. Disponível em: <http://publicadireito.com.br/artigos/?cod=8ce13ccd4a1b7b88>. Acesso em: 23 fe. 2017.

BAUMAN, Zygmunt. Modernidade Líquida. Tradução de Plínio Dentzien. Rio de Janeiro: Zahar, 2001.

BECK, Ulrich. O que é Globalização? Equívocos do Globalismo: Respostas à Globalização. Tradução de André Carone. São Paulo: Paz e Terra, 1999.

BELL, Daniel. O Advento da Sociedade Pós-Industrial. São Paulo: Cultrix, 1973.

BONILLA, M. H. Escola aprendente: para além da sociedade da informação. Rio de Janeiro: Quartet, 2005.

BRASIL. Presidência da República. Secretaria de Comunicação Social. Pesquisa Brasileira de Mídia 2015: hábitos de consumo de mídia pela população brasileira. - Brasília: Secom, 2014.

Constituição da República Federativa do Brasil.Senado Federal.

Brasília, 1988. Disponível em: <http://www.planalto.gov.br/ccivil_03/Constituicao/Constituicao.htm>. Acesso em: 23 fev. 2017.

Lei $n^{\circ}$ 8.080, de 19 de setembro de 1990. Dispõe sobre as condições para a promoção, proteção e recuperação da saúde, a organização e o funcionamento dos serviços correspondentes e dá outras providências. Disponível em: <http://www.planalto.gov.br/ccivil_03/leis/L8080.htm>. Acesso em: 18 mar. 2017.

CGI, Comitê Gestor da Internet no Brasil. Pesquisa TIC Domicílios 2015: Pesquisa sobre o uso das tecnologias da informação e comunicação nos domicílios brasileiros [livro eletrônico]: TIC domicílios 2015 = Survey on the use of information and communication technologie in brazilian households: ICT households 2015 / Núcleo de Informação e Coordenação do Ponto BR [editor]. - São Paulo: Comitê Gestor da Internet no Brasil, 2016.

CASTELLS, Manuel. A Galáxia da Internet: reflexões sobre a internet, negócios e a sociedade. Traduzido por Maria Luiza X. de A. Borges. Rio de Janeiro: Jorge Zahar, 2003.

. A sociedade em rede. A era da informação: economia, sociedade e cultura. v. 1, 9 ed. São Paulo: Paz e Terra, 1999.

CARDOSO, Gustavo. A Mídia na Sociedade em Rede: filtros, vitrines, notícias. Rio de Janeiro: Editora FGV, 2007.

CANCLINI, Nestor García. Leitores, espectadores e internautas. Tradução de Ana Goldberger. São Paulo: lluminuras, 2008.

CARVALHEIRO, José da Rocha; MARQUES, Maria Cristina Costa; MOTA, André. A Construção da Saúde Pública no Brasil no século XX. In: ROCHA, Aristides Almeida; CESAR, Chester Luiz Galvão. Saúde Pública: bases conceituais. São Paulo: Atheneu, 2008. 
A SOCIEDADE EM REDE E AS DOENÇAS EMERGENTES:

UMA PROPOSTA BASEADA NA UTILIZAÇÃO EXCESSIVA DAS TECNOLOGIAS DIGITAIS

CONTRERA, Malena Segura. Mídia e Pânico: saturação da informação, violência e crise cultural na mídia. São Paulo: Annablume, 2002.

CAPPARELLI, Sérgio; RAMOS, Murilo César; SANTOS, Suzy. A nova televisão no Brasil e na Argentina. In: CAPPARELLI et all. Enfim, sós: a nova televisão no Cone Sul. Porto Alegre: LPM, 1999.

DALLARI, SG. O direito sanitário como campo fundamental para vigilância sanitária. In: Vigilância Sanitária: textos e contextos. São Paulo: Cecovisa, 2007.

DE MAIS, Domenico. A sociedade pós-industrial. In: (Org). A sociedade pós-industrial. 3. Ed. São Paulo: Editora SENAC, p. 11-98, 2000

DRUCKER, Peter. Sociedade pós-capitalista. Traduzido por Nivaldo Montigelli Junior. São Paulo: Pioneira, 1994.

ERGONOMIA, DORTE ou LER - Lesões causadas por esforços repetitivos ou traumas no sistema músculo-esquelético. Disponível em: <http://www.ergonomia.com.br/htm/ler.ht>. Acesso em: 21 Fev. 2017.

FONSECA, Ellen Carrara; ARRUDA, Gustavo Viani; ROCHA, Eduardo Milani. Olho seco: etiopatogenia e tratamento. In: Arq Brasil Oftamol, 2010;73(2): pag. 197-203. Disponível em: <http://www.scielo.br/pdf/abo/v73n2/ v73n2a21.pdf>. Acesso em: 03 mai. 2017.

GIDDENS, Anthony. Mundo em descontrole: o que a globalização está fazendo de nós. Tradução de Maria Luiza X. de A. Borges. Rio de Janeiro: Record, 2000.

MATTELART, Armand. La mundializacíon de la comunicaíon. Traduçãode Orlando Carreno. Barcelona: Paidós, 1998.

LUZ, MT. Novos saberes a prática em saúde coletiva: estudos sobre as racionalidades médicas e atividades corporais. São Paulo: Hucitec, 2003.

POSTMAN, Neil. Tecnopólio: A rendição da cultura à tecnologia. São Paulo: Nobel, 1994.

RECUERO, Raquel. Redes Sociais na Internet. Porto Alegre: Sulina, 2009.

REVISTA BRASILEIROS. A Internet estaria nos deixando doentes? 23 Out. 2013. Disponível em: <http://www. revistabrasileiros.com.br/2013/10/23/a-internet-estaria-nos-deixando-doentes/\#. U8KLQ_InCH0>. Acesso em: 21 Fev. 2017.

SANCHES, Oscar Adolfo. Governo Eletrônico no Estado de São Paulo. São Paulo: Série Didática n. 7, 2003.

VELOSO, Renato. Tecnologias da Informação e Comunicação: desafios e perspectivas. São Paulo: Saraiva, 2011.

VOSGERAU, Dilmeire Sant'anna Ramos; BERTONCELLO, Ludhiana. Inclusão digital na infância: o uso e a apropriação das TICs pelas crianças brasileiras. In: Alexandre F. Barbosa (Coord. Executivo e Editorial). Pesquisa sobre o uso das tecnologias da informação e comunicação no Brasil: 2005-2009 = Survey on the use of information and communication Technologies in Brazil: 2005-2009. Tradução de Karen Brito. São Paulo: Comitê Gestor da Internet no Brasil, 2010.

ZIONI, Fabiola; ALMEIDA, Eurivaldo Sampaio de. Políticas Públicas e Sistemas de Saúde: a Reforma Sanitária e o SUS. In: ROCHA, Aristides Almeida; CESAR, Chester Luiz Galvão. Saúde Pública: bases conceituais. São Paulo: Atheneu, 2008.

WEIL, Pierre. A normose informacional. In: Ciência da Informação. V. 29, n.2. Brasília. Maio-agosto, 2000. 